\title{
Current status of intestinal Schistosomiasis and soil- transmitted helminthiasis among primary school children in Adwa Town, Northern Ethiopia
}

\author{
Lemlem Legesse ${ }^{1}$, Berhanu Erko ${ }^{2}$, Asrat Hailu ${ }^{3}$
}

\begin{abstract}
Background: Epidemiological baseline information on the prevalence and intensity of parasitic infections in a given locality is a prerequisite for development and evaluation of sound control strategies.

Objective: To determine the current status of schistosomiasis and soil-transmitted helminthiasis among primary school children in Adwa Town, northern Ethiopia.

Methods: A cross-sectional epidemiological study was carried out in eight primary schools in Adwa Town between October and November 2007. Fecal samples of 386 school children in the age group 7-18 were collected and microscopically examined using the Kato-Katz and formol-ether concentration methods. A questionnaire was used to identify determinants for Schistosoma mansoni and soil-transmitted helminth infections.

Results: The most prevalent intestinal parasitic infection among primary school children in Adwa Town as determined by Kato-Katz (58.7\%) and formol ether concentration (60.6\%) methods was intestinal schistosomiasis, with an overall intensity of 95.8 eggs per gram of stool. The prevalence of $S$. mansoni infection was higher in males (70.7\%) than in females (57\%), as determined by both methods. Less common parasites observed included Ascaris lumbricoides, hookworm species, Hymenolepis nana, Strongyloides stercoralis, and Entamoeba histolytica/dispar.

Conclusion: The residents of Adwa Town represent a high-risk community with respect to intestinal schistosomiasis. Hence, mass praziquantel administration to school-age children and all adults considered to be at risk is required once a year until the level of infection falls below the level of public health importance. There is also a need to supplement chemotherapy with other measures such as environmental sanitation and health education to make the impact of chemotherapy sustainable. [Ethiop. J. Health Dev. 2010;24(3):191-197]
\end{abstract}

\section{Introduction}

Schistosomiasis and soil-transmitted helminthiasis (STHs) are chronic and insidious diseases producing long -term effects on man (1). They are among the most common parasitic infections in the world (2). Approximately 300 million people with heavy helminth infection suffer from severe morbidity that results in more than 150,000 deaths annually (3). Infection rates are higher in children than adults (4). Recent global prevalence estimate shows that $S$. mansoni infects 67 million, A. lumbricoides 1.221 billion, T. trichiura 795 million and hookworm 740 million people (5).

In Ethiopia, many surveys carried out on intestinal schistosomiasis and soil-transmitted helminthiasis have shown that helminthic infections represent a major public health concern. Studies conducted on schistosomiasis in Ethiopia show that prevalence rates are generally higher among males than females $(6-10)$. Moreover, results of epidemiological studies in different parts of Ethiopia showed the characteristically wide dispersion of schistosomiasis cases and high egg counts among school children $(11,12)$.
The epidemiological study conducted in Adwa in the late 1960 s using the formol ether concentration (FEC) method reported the overall prevalence of $83.8 \%, 42.8 \%$ and $6.2 \%$, for S. mansoni, A. lumbricoides, and $T$. trichiura infections, respectively, for school age children aged $7-15$ years (13). A schistosomiasis pilot control trial using mainly the molluscicides endod (Phytolacca dodecandra) and Bayluscide was instituted in Adwa Town in northern Ethiopia from 1962 to 1972 and decreased the prevalence of $S$. mansoni infection from $64 \%$ in 1969 to $43.3 \%$ in 1972 in the total population and even more sharply in 1-6 year old children (13). In a more recent survey conducted in the early 1990 s, a $S$. mansoni prevalence of $62 \%$ was reported for the general population using the Kato-Katz technique (8).

Water-based development schemes being initiated in several areas and population mobility for settlement and job opportunities might have an impact on the epidemiology of intestinal schistosomiasis in Ethiopia $(12,14)$. In Adwa Town, the latest study was conducted by Birrie et al. (8) in the early 1990s. Since then, the status of the disease has not been known in the area.

\footnotetext{
${ }^{\mathrm{T}}$ Tigray Regional Laboratory, P. O. Box 7, Tel: +251-0344400986/0914722629, Fax: +251-4408830, Mekelle, Ethiopia;

${ }^{2}$ Aklilu Lemma Institute of Pathobiology, Addis Ababa University, P. O. Box 1176, Tel: +251-11 2763091, Fax: +251-11 -2755296, Addis Ababa, Ethiopia;

${ }^{3}$ Faculty of Medicine, Addis Ababa University, P. O. Box 9086, Tel: +251-11 6557248/0911480993, Fax: +251-1 $5512 n 00 \quad \Delta$ ddic $\Delta$ haha Fthinnis
} 
Therefore, the objective of this study was to determine the magnitude of intestinal schistosomiasis and soiltransmitted helminthiasis and associated determinants among primary school children in Adwa Town.

\section{Methods}

Study Areas: The study was carried out in October and November 2007 in the Adwa Town, Tigray Regional State, northern Ethiopia, located at a distance of $1006 \mathrm{~km}$ from Addis Ababa (Fig. 1). The Town of Adwa has an altitudinal range of 1800-1900 meters. The annual rainfall is $500 \mathrm{~mm}$ to $600 \mathrm{~mm}$, reaching its peak from July to August. The temperature is warm and ranges from $27^{\circ} \mathrm{C}$ to $28^{\circ} \mathrm{C}$. The Town of Adwa is traversed by streams and rivers which constitute the major sources of $S$. mansoni infection. The town had a population of approximately 46,645 inhabitants in 2006, of whom 22,737 were males and 23,908 were females (15).

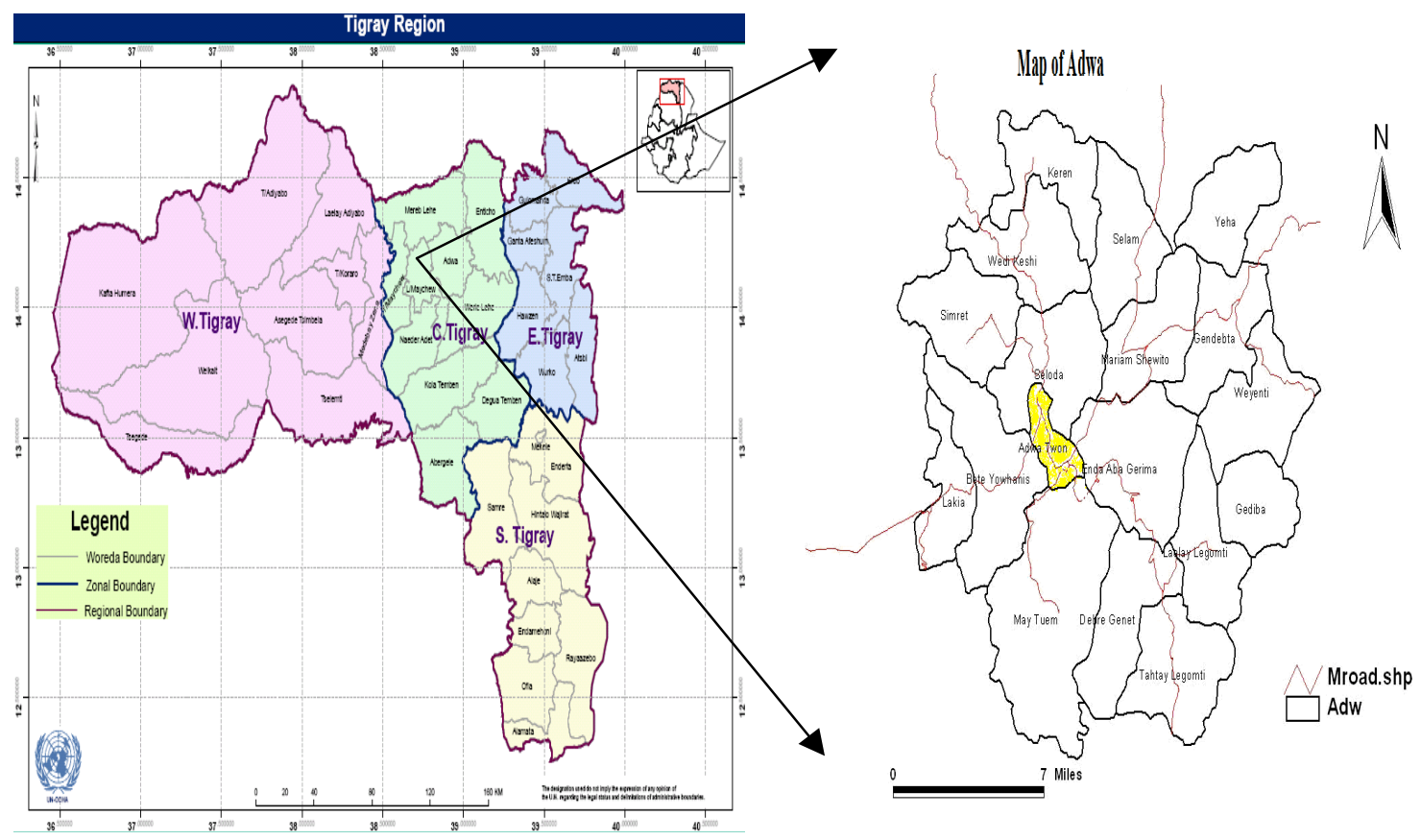

Figure 1: The location of Adwa Town

Source: (www.ocha-eth.org/Maps/downloadables/TIGRAY.pdf.)

Study population: The study population included children attending grade one to eight in eight primary schools in the Adwa Town. Children were considered for the study since the peak prevalence of schistosomiasis and soil-transmitted helminthiasis (except hookworm infections) is characteristically found in children.

Sample size was determined based on the previous study done on prevalence $(66 \%)(8)$. The minimum sample size required for analysis was calculated using the $95 \%$ confidence interval with $5 \%$ margin error. Additional $10 \%$ was allowed for non response. Using the formula ( $n$ $=z^{2} p(1-p) / d^{2}$, where $n=$ sample size, $z=z$ statistic for $a$ level of confidence $(z=1.96$ at $95 \% \mathrm{CI}), \mathrm{p}=$ expected prevalence or proportion $(\mathrm{p}=0.66), \mathrm{d}=$ precision (if $5 \%$, $\mathrm{d}=0.05)$, the sample size was computed to be 380 . However, because excess manpower resources were available, the researchers included six additional students, increasing the sample size to 386. Sampling with probability proportional to size was used to select study subjects using the master list of each school. The first step was selection of classes from each primary school with proportional allocation to size of classes. The second step involved the selection of study subjects using simple random sampling.
Stool Collection and Examination: During stool sample collection, each student completed a brief questionnaire, which was administered by trained interviewers in the local language. At the time of interview, fingernails of the children were also inspected to observe whether they were trimmed or not. Following the questionnaire, each child was supplied with a plastic sheet, applicator stick, and toilet paper and instructed to bring a stool sample of their own. A portion of the stool sample (about 1-2gm) was collected in labelled screw capped vials pre-filled with $10 \%$ formalin. In addition, a portion of the specimen was processed using a $41.7 \mathrm{mg}$ Kato-Katz template (18), examining two slides per stool sample.

Data Analysis: Data was entered in EpiInfo Version 5.0 statistical package and exported to SPSS 11.0 for Windows for statistical analysis. Mean egg counts for the two samples were converted into eggs per gram (epg) and geometric mean was computed.

Ethical Considerations: The project obtained ethical clearance from the Ethical Clearance Committee of the Department of Microbiology, Immunology and Parasitology, and Medical Faculty Research and Publications Committee, Addis Ababa University. Fthinn I Hoalth Now, on1n.74(2) 
Permission was also obtained from Tigray Regional Health Bureau and school directors to conduct the study. Written consent was also obtained from the parents of the study subjects and those who were found positive for $S$. mansoni were treated with praziquantel at a single dose of $40 \mathrm{mg} / \mathrm{kg}$ body weight (19). Children who were found positive for STHs were treated with albendazole (400mg). Children who were found positive for Hymenolepis nana infection were also treated with praziquantel.

\section{Results}

Out of the total 386 school children, stool examination results of children from Assefa Mamo Primary School were excluded from analysis because they were only five in number. Among the selected students, 167 (43.8\%) were males and $214(56.2 \%)$ were females. The mean age was 11.73 years, with age range of 7 to 18 years.

Results of Kato-Katz and formol-ether concentration methods were obtained for 386 school children. The stool samples of six students were not processed by the KatoKatz technique as they provided loose stool, but were processed by the formol-ether concentration technique. Pooling the results of the two diagnostic approaches increased the prevalence of both $S$. mansoni and STH infection (Table 1).

Table 1: Prevalence of intestinal parasites as determined by Kato-Katz and formol-ether concentration methods among school children in Adwa Town, northern Ethiopia 2007

\begin{tabular}{|c|c|c|c|c|c|}
\hline \multirow{3}{*}{ Parasite species } & \multicolumn{5}{|c|}{ Number Positive (\%) } \\
\hline & \multirow{2}{*}{$\begin{array}{l}\text { Kato-Katz } \\
\text { method }\end{array}$} & \multirow{2}{*}{$\begin{array}{l}\text { Formol-ether } \\
\text { concentration }\end{array}$} & \multicolumn{3}{|c|}{ Combined results } \\
\hline & & & Male $(n=167)$ & Female $(n=214)$ & $\begin{array}{l}\text { Both sex } \\
(n=381)\end{array}$ \\
\hline S. mansoni & $220(58.7)$ & $234(60.6)$ & $118(70.7)$ & $122(57.0)$ & $240(63.0)$ \\
\hline A. lumbricoides & $24(6.4)$ & $23(6.0)$ & $12(7.3)$ & $12(5.7)$ & $24(6.4)$ \\
\hline Hookworm sp. & $0(0.0)$ & $4(1.0)$ & $1(0.6)$ & $3(1.4)$ & $4(1.0)$ \\
\hline H. nana & $10(2.7)$ & $25(6.6)$ & $14(8.4)$ & $17(7.9)$ & $31(8.1)$ \\
\hline S. stercoralis & $0(0.0)$ & $1(0.3)$ & $0(0.0)$ & $1(0.5)$ & $1(0.3)$ \\
\hline E. histolytica/dispar cyst & $0(0.0)$ & $7(1.8)$ & $5(2.9)$ & $2(0.9)$ & $7(1.8)$ \\
\hline
\end{tabular}

Of the total 381 children examined, 263 (69\%) were found positive for various intestinal parasites (after pooling the results of the two diagnostic methods). The most prevalent parasitic infection was intestinal schistosomiasis $(63 \%)$ due to $S$. mansoni. The prevalence of $S$. mansoni was higher among males (70.7\%) than females $(57.0 \%)$ and the difference was statistically significant $(\mathrm{p}<0.05)$. The number of school children with detectable soil-transmitted helminth infection was low. While $24(6.4 \%)$ children had A. lumbricoides, the other four $(1.0 \%)$ had hookworm with no significant gender difference. There was no single case of $T$. trichiura infection. Other rare parasites encountered in this study were S. stercoralis $(0.3 \%), H$. nana $(8.1 \%)$ and cyst of
E. histolytica / dispar (1.8\%) (Table 1).

As shown in Table 2, $S$. mansoni infection was encountered in all schools. The highest prevalence of $S$. mansoni infection was reported for Tsion School $43(70.5 \%)$, while the lowest $10(20 \%)$ was reported for Adwa School. On the other hand, infection due to $A$. lumbricoides was found in six of the eight schools, with prevalence ranging from $(1.6 \%)$ in Tsion to $(14.0 \%)$ in May Guagua. The intensity of $S$. mansoni infection ranged from 57 epg in Soloda to 142 epg in Adi Abeto. Similarly, the intensity of $A$. lumbricoides infection ranged from $27 \mathrm{epg}$ in May Guagua to 1052 epg in Haleka Teweldemedhine School.

Table 2: Prevalence and intensity of intestinal schistosomiasis and ascariasis using Kato-Katz method in 8 elementary schools in Adwa Town, northern Ethiopia, 2007

\begin{tabular}{|c|c|c|c|c|c|c|c|}
\hline \multirow{3}{*}{ School } & \multicolumn{3}{|c|}{ No. Examined } & \multicolumn{4}{|c|}{ Positive for } \\
\hline & \multirow[b]{2}{*}{ Male } & \multirow[b]{2}{*}{ Female } & \multirow[b]{2}{*}{$\begin{array}{l}\text { Total no. } \\
\text { examined }\end{array}$} & \multicolumn{2}{|c|}{ S. mansoni } & \multicolumn{2}{|c|}{ A. Iumbricoides } \\
\hline & & & & No. (\%) & epg & No. (\%) & Epg \\
\hline May Guagua & 28 & 22 & 50 & $33(66.0)$ & 108 & $7(14.0)$ & 27 \\
\hline Adi Maheleka & 22 & 24 & 46 & $31(69.0)$ & 111 & $2(4.4)$ & 38 \\
\hline Adwa & 26 & 25 & 51 & $10(20.0$ & 134 & $0(0)$ & 0 \\
\hline May Tsadik & 26 & 37 & 63 & $36(57.1)$ & 71 & $8(12.7)$ & 91.6 \\
\hline Tsion & 23 & 40 & 63 & $43(70.5)$ & 110 & $1(1.6)$ & 600 \\
\hline Adi Abeto & 18 & 28 & 46 & $26(56.5)$ & 142 & $0(0)$ & 0 \\
\hline Soloda & 13 & 26 & 39 & $27(69.2)$ & 57 & $4(10.3)$ & 32.3 \\
\hline $\begin{array}{l}\text { HalekaTewelde } \\
\text { medhine }\end{array}$ & 11 & 12 & 23 & $14(66.7)$ & 74 & $2(9.5)$ & 1051.6 \\
\hline Total & 165 & 210 & 375 & $220(58.7)$ & 96 & $24(6.4)$ & 62.4 \\
\hline
\end{tabular}


The prevalence of $S$. mansoni infection was high (>50\%) in all age groups (Table 3), while the peak intensity was observed in the 15-19 age group (128 epg), followed by the 5-9 age group (112 epg). The peak intensity of $A$. lumbricoides infection was 600 epg in the age group 1519,71 epg in the 10-14 age group and 25 epg in the 5-9 age group.

Classes of intensity of S. mansoni and A. lumbricoides infections for different age groups are shown in Table 3. For S. mansoni infection, the prevalence of light, moderate and heavy infections were $32 \%, 21.1 \%$ and 5.1\%, respectively. All $A$. lumbricoides were light infections. The highest egg counts for $S$. mansoni and $A$. lumbricoides were 1464 and 2040 epg, respectively.
Table 4 shows the number of children with either single or double infections; 199 (53.1\%) children had a single infection with $S$. mansoni, while $8(2.1 \%)$ and $4(1.0 \%)$ were infected with $A$. lumbricoides and hookworm, respectively. Double infections were encountered in 15 (4\%) specimens and they were a combination of $S$. mansoni and A. lumbricoides. The prevalence of single infections as well as double among males and females were similar.

Among the potential determinants studied, the prevalence of $S$. mansoni infection was found to be significantly associated with gender, swimming habit, and contact with water during crossing of the stream. On the other hand, $S$. mansoni infection was not significantly associated with age (Table 6).

Table 3: Classes of intensity (GM) of S. mansoni and A. lumbricoides infections by age among Adwa Town school children, northern Ethiopia, 2007

\begin{tabular}{|c|c|c|c|c|c|c|c|}
\hline \multirow{4}{*}{ Age(yrs) } & \multirow{4}{*}{$\begin{array}{l}\text { No. } \\
\text { examined }\end{array}$} & \multicolumn{4}{|c|}{ S. mansoni } & \multicolumn{2}{|c|}{ A. lumbricoides } \\
\hline & & Negative & Light & Moderate & Heavy & Negative & Light \\
\hline & & 0 & $1-99 \mathrm{epg}$ & $100-399 \mathrm{epg}$ & $\geq 400 \mathrm{epg}$ & 0 & 1-4999 epg \\
\hline & & No $(\%)$ & No (\%) & No $(\%)$ & No $(\%)$ & No $(\%)$ & No $(\%)$ \\
\hline $5-9$ & 46 & $16(34.8)$ & $17(37.0)$ & $9(19.6)$ & $4(8.7)$ & 41(89.1) & $5(10.9)$ \\
\hline $10-14$ & 303 & $129(43.0)$ & $96(31.7)$ & $64(21.1)$ & $14(4.6)$ & $285(98.0)$ & $18(5.9)$ \\
\hline $15-19$ & 26 & $10(38.5)$ & $7(26.9)$ & $8(30.8)$ & $1(3.8)$ & $25(96.2)$ & $1(3.8)$ \\
\hline Total & 375 & 155(41) & $120(32)$ & $81(21.1)$ & $19(5.1)$ & $351(93.6)$ & $24(6.4)$ \\
\hline
\end{tabular}

Table 4: Double and single infections with S. mansoni, A. lumbricoides and hookworms among elementary school children in Adwa Town, northern Ethiopia, 2007

\begin{tabular}{llll}
\hline $\begin{array}{l}\text { Helminth } \\
\text { species }\end{array}$ & Male & Female & Both genders \\
\hline $\mathrm{Sm}, \mathrm{Al}$ & $\mathbf{N}(\%)$ & $\mathbf{N}(\%)$ & $\mathbf{N}(\%)$ \\
$\mathrm{Sm}$ & $9(2.4 \%)$ & $6(1.6 \%)$ & $15(4.0 \%)$ \\
$\mathrm{Al}$ & $97(25.8 \%)$ & $102(27.2 \%)$ & $199(53.1 \%)$ \\
$\mathrm{Hw}$ & $2(0.5 \%)$ & $6(1.6 \%)$ & $8(2.1 \%)$ \\
\hline
\end{tabular}

$\mathrm{Sm}=$ S. mansoni; $\mathrm{Al}=\mathrm{A}$. lumbricoides; $\mathrm{Hw}=\mathrm{hookworm} ; \%=$ of the total sample

The minimum duration of stay in Adwa for the study participants was one year and the majority of them were born and had lived in the town. Regarding religion, Orthodox Christians were the largest group [348 (91.3\%)]. Most of the children 357(93.7\%) used tap water for drinking and cooking. Only $6.3 \%$ of the children obtained water for those purposes from streams (Table 5), 14 (58.3\%) of them making two trips per day.

Most parents of the children $(73.5 \%)$ had toilets in their house. The remaining $26.5 \%$ had no access to toilets and reportedly defecate in open field. Regarding schools, Haleka Teweldemedhine, had no latrines but all the other schools had tap water. Ninety percent of the children reported to wash their hands after defecation, $75.6 \%$ of the children claimed to have trimmed finger nails and $75.3 \%$ of the children claimed to have swum in streams. More than four-fifth $(82.4 \%)$ of the children $(n=314)$ had water contact while crossing streams.
Out of the 381 children interviewed, $24.7 \%$ claimed to have washed clothes in streams. The majority of children $(94.0 \%)$ bathed at home using piped water, while the remaining $23(6.0 \%)$ bathed in streams. All children wore shoes regularly; (19.7\%) wore protective shoes and $(80.3 \%)$ wore sandals.

Multiple logistic regression was performed for variables that were significantly associated with $S$. mansoni in univariate analysis. After adjusting for males, swimming habit in the rainy season and contact with water while crossing streams remained significantly associated with $S$. mansoni infection (Table 6). Males were 1.72 times (95\% CI: $1.1,2.6)$ more likely to be infected with $S$. mansoni than females. Children with swimming habit in the rainy season were 2.13 times (95\% CI: $1.27,3.5)$ more likely to acquire $S$. mansoni infection. Students who reportedly had while crossing streams were 1.85 times $(95 \%$ CI: $1.1,3.2)$ more likely to acquire $S$. mansoni infection. 


\section{Discussion}

The endemicity of schistosomiasis has long been established in Adwa Town. In the early 1990s, Birrie et al. (8) reported a prevalence of $62 \%$ and intensity of 577 epg for $S$. mansoni infection using Kato-Kat technique. In the present study, the overall prevalence of $58.7 \%$ by Kato and $60.6 \%$ by FEC, and intensity of 96 epg were observed among school children in the same Town. The present prevalence rate was relatively lower, while the intensity of infection was much lower than those reported in the 1990s. This may be attributed to improved sanitation or provision of safe water. At present, nearly all houses have piped water and this might have reduced water contact activities at least for domestic purposes.

In the present study, the very high prevalence, but low intensity of schistosomiasis among school children in Adwa is noteworthy. Low intensity of infection relative to prevalence was also reported by Barakat et al. (20), who suggested that their Egyptian community would be at high risk of contracting the infection. It must be remembered, however, that intense exposure is necessary for high intensity of infection to develop.

Table 5: Results of questionnaire survey on determinants for schistosomiasis and soil-transmitted helminthiasis in Adwa Town, northern Ethiopia 2007

\begin{tabular}{|c|c|c|}
\hline Variables & Frequency & $\%$ \\
\hline Age group(Years) & 47 & 12.3 \\
\hline $5-9$ & 307 & 80.6 \\
\hline $10-14$ & 27 & 7.1 \\
\hline \multicolumn{3}{|l|}{$15-19$} \\
\hline \multicolumn{3}{|l|}{ Gender } \\
\hline Male & 167 & 43.8 \\
\hline Female & 214 & 56.2 \\
\hline \multicolumn{3}{|l|}{ Religion } \\
\hline Muslim & 33 & 8.7 \\
\hline Christian & 348 & 91.3 \\
\hline \multicolumn{3}{|c|}{ Water source for domestic purposes } \\
\hline Tap & 357 & 93.7 \\
\hline Stream & 24 & 6.3 \\
\hline \multicolumn{3}{|c|}{ Laundering in streams } \\
\hline Yes & 94 & 24.7 \\
\hline No & 287 & 75.3 \\
\hline \multicolumn{3}{|l|}{ Bathing } \\
\hline Home & 358 & 94.0 \\
\hline Stream & 23 & 6.0 \\
\hline \multicolumn{3}{|l|}{ Swimming habit } \\
\hline Yes & 287 & 75.3 \\
\hline No & 94 & 24.7 \\
\hline \multicolumn{3}{|l|}{ Freq of swimming } \\
\hline Always & 133 & 46.3 \\
\hline Sometimes & 154 & 53.7 \\
\hline \multicolumn{3}{|c|}{ Contact with stream water while crossing } \\
\hline Yes & 314 & 82.4 \\
\hline No & 67 & 17.6 \\
\hline \multicolumn{3}{|c|}{ Frequency of crossing stream } \\
\hline Always & 72 & 22.9 \\
\hline Sometimes & 242 & 77.1 \\
\hline \multicolumn{3}{|l|}{ Defecation site } \\
\hline Indoor latrine & 280 & 73.5 \\
\hline Open field & 101 & 26.5 \\
\hline \multicolumn{3}{|c|}{ Washing hands after defecation } \\
\hline Yes & 343 & 90.0 \\
\hline No & 38 & 10.0 \\
\hline \multicolumn{3}{|c|}{ Shoe wearing habit/shoes type } \\
\hline Protective & 75 & 19.7 \\
\hline Sandals & 306 & 80.3 \\
\hline \multicolumn{3}{|c|}{ Finger nails trimmed } \\
\hline Yes & 288 & 75.6 \\
\hline No & 93 & 24.4 \\
\hline
\end{tabular}




\begin{tabular}{|c|c|c|c|c|c|}
\hline \multirow{2}{*}{\multicolumn{2}{|c|}{ Determinant factors }} & \multirow{2}{*}{\multicolumn{2}{|c|}{ Number (\%) }} & \multirow{2}{*}{$\begin{array}{l}\text { OR,95\%Cl } \\
\text { (Crude) }\end{array}$} & \multirow{2}{*}{$\begin{array}{l}\text { OR,95\%CI } \\
\text { (Adjusted) }\end{array}$} \\
\hline & & & & & \\
\hline \multirow[t]{3}{*}{ Age Group } & $\begin{array}{l}5 \text { to } 9 \\
(n=46)\end{array}$ & $16(34.8)$ & $30(65.2)$ & $0.89(0.34,2.35)$ & $0.89(0.31,2.54)$ \\
\hline & $\begin{array}{l}10 \text { to } 14 \\
(n=303)\end{array}$ & $129(42.6)$ & $174(57.4)$ & $0.84(0.37,1.91)$ & $0.77(0.33,1.83)$ \\
\hline & $\begin{array}{l}15 \text { to } 19 \\
(n=26)\end{array}$ & 1038.5) & $16(61.5)$ & 1.00 & 1.00 \\
\hline \multirow[t]{2}{*}{ Sex } & $\begin{array}{l}\text { Male } \\
(n=165)\end{array}$ & $53(32.1)$ & $112(67.9)$ & $1.99(1.31,3.05)^{*}$ & $1.72(1.12,2.67)^{*}$ \\
\hline & $\begin{array}{l}\text { Female } \\
(\mathrm{n}=210)\end{array}$ & 102(48.6) & $108(51.4)$ & 1.00 & 1.00 \\
\hline \multirow[t]{2}{*}{ Swimming habit } & $\begin{array}{l}\text { Yes } \\
(\mathrm{n}=283)\end{array}$ & $101(35.7)$ & $182(64.3)$ & $2.56(1.58,4.14)^{*}$ & $2.12(1.27,3.54)^{*}$ \\
\hline & $\begin{array}{l}\text { No } \\
(n=92)\end{array}$ & $54(58.7)$ & $38(41.3)$ & 1.00 & 1.00 \\
\hline \multirow{2}{*}{$\begin{array}{l}\text { Water contact } \\
\text { while crossing } \\
\text { streams }\end{array}$} & $\begin{array}{l}\text { Yes } \\
(n=308)\end{array}$ & $117(38.0)$ & $191(62.0)$ & $2.14(1.25,3.65)$ * & $1.85(1 \cdot 10,3 \cdot 23)^{\star}$ \\
\hline & $\begin{array}{l}\text { No } \\
(n=67)\end{array}$ & $38(56.7)$ & $29(43.3)$ & 1.00 & 1.00 \\
\hline
\end{tabular}

The prevalence of STHs among school children was low and the community represents a low risk community in this regard. The 1960s survey conducted in Adwa reported higher prevalence of STH infections for children in the age group $7-15$, that is, $71 \%, 3.7 \%, 34.9 \%$ for $A$. lumbricoides, hookworm and T. trichiura, respectively (13). The present lower prevalence of STH infections could be due to annual deworming of under five year olds since 2000 by the MoH and UNICEF or improved sanitation and the provision of clean water. However, indepth studies are required to clearly explain the currently low rates of STHs in Adwa Town.

Analysis of the intensity of infection for S. mansoni and A. lumbricoides showed that the intensity was light to moderate for $S$. mansoni and light for A. lumbricoides. The majority of the children were negative for $A$. lumbricoides and few excreted large quantities of eggs in $S$. mansoni infection. This is consistent with the findings of many investigators, including. Palmer and Bundy (21), who found that the infection is over-dispersed, with a minority of the population typically excreting large quantities of eggs while the majority has light infections, excreting very few eggs.

Co-infection of $S$. mansoni and A. lumbricoides were observed in $4.0 \%$ of the total examined population. This figure is similar to co-infections (4.4\%) reported by Erko and Medhin (22), but is much lower than the result reported by Jemaneh (23) among school children in Dembia in the Lake Tana Basin (20.3\%).

The prevalence of $S$. mansoni infection was higher in male than female children. This difference has also been observed in other studies $(24,25)$ and may be explained by the fact that male children stay most of the time outdoors, playing and swimming in cercariae-infested water compared to females who seldom participate in such activities. This is also supported by the fact that only swimming habit and contact with water while crossing streams were identified as important determinants for S. mansoni infection.

In conclusion, the present study shows that intestinal schistosomiasis was the most prevalent parasitic infection in Adwa Town, with infection levels remaining as high as in the 1960s. This calls for immediate mass praziquantel administration to all eligible groups once a year until the prevalence of the disease falls below the level of public health importance. In addition, preventive measures such as provision of clean water and sanitary facilities as well as health education, all of which have been proven to be effective in reducing schistosomiasis transmission in many countries, should in place to sustain the impact of drug treatment. Since the magnitude of STHs was below the level of public health importance, they can be dealt with on a case-by-case basis and the above non-disease specific measures can also help in maintaining the low level of STHs in Adwa.

\section{Acknowledgements}

We would like to acknowledge Dr. Gebrabe Barnabas for his cooperation in facilitating sponsorship and Tigray Regional Health Bureau staffs for their support. We are grateful to Dr. Alemayehu Worku, Mr Berhane Haileselassie and Mr Hailemariam Kassahun for their assistance in statistical analysis and consultation. We would also like to thank Adwa health center administrative staff, Sister Elsabete Assefa and the laboratory technicians Miss Alemtsehay Tareke, Mrs Weldegabriel Hayelom and Mrs Teklewoini Kahssu for their commitment in the field work and behind the bench. This study was funded by the School of Graduate Studies, Addis Ababa University and the Global Fund. 


\section{References}

1. Stephenson LS, Latham MC, Ottesen EA. Malnutrition and parasitic helminth infections. Parasitology 2000;121:23-28.

2. Okpala HO, Agwu E, Agba MI, Chimezie OR, Nwobu GO, Ohihoin AA. A survey of the prevalence of schistosomiasis among pupils in Apata and Laranto areas in Jos, Plateau state. Online $J$ Health Allied Scs 2004;1:1.

3. Montresor A, Crompton, DWT, Gyorkos TW, and Savioli L. Helminth Control in School-Age Children: A Guide for Managers of Control Programmes. Geneva: WHO; 2002:19-20.

4. WHO. Prevention and Control of Schistosomiasis and Soil-Transmitted Helminthiasis. 2004. $\mathrm{WHO} / \mathrm{CDS} / \mathrm{CPE} / \mathrm{PVC} / 2004.9$.

5. De Silva NR, Brooker S, Hotez PJ, Montresor A, Engles D, and Savioli L. Soil-transmitted helminth infections: Updating the global picture. Trends in Parasitology 2003;19:547-51.

6. Kloos H, Lo CT, Birrie H, Ayele T, Tedla S, and Tsegay F. Schistosomiasis in Ethiopia. Soc Sci Med 1988;26(8):803-827.

7. Shibru, T. Helminthiasis in Ethiopia: A review. SINET .Ethiop J Sci 1989;12:25-48.

8. Birrie H, Woldemichael T, Redda A, Chane T. The status of Schistosoma mansoni and snail hosts in Tigray and Northern Wello regions, Northern Ethiopia. Ethiop Med J 1994;32:245-253.

9. Assefa T, Woldemicheal T, Dejene A. Intestinal parasitism among students in three localities in south Wello, Ethiopia. Ethiop J Health Dev 1998;12:231 235.

10. Tadesse G. The prevalence of intestinal helminthic infections and associated risk factors among school children in Babile town, eastern Ethiopia. Ethiop $J$ Health Dev 2005;19:140-147.

11. Woldemichael $\mathrm{T}$, and Kebede A. Newly identified endemic areas of intestinal schistosomiasis in Tigray, Northern Ethiopia. Ethiop Med J 1996; 34:73-82.

12. Jemaneh L. The epidemiology of intestinal schistosomiasis and soil-transmitted helminths in elementary school children from the South Gonder Zone of Amhara National Regional State, Ethiopia. Ethiop Med J 2000;38:105-118.

13. Flemming MB, Goll $\mathrm{PH}$. Progress report on schistosomiasis (bilharia) control in a northern Ethiopian community. Proc Afro-Asian Symp Chemother Schist 1971;665-677.
14. Erko B, Gemetchu T, Gemeda N,and Dessie S. Transmission of intestinal schistosomiasis in Addis Ababa. E Afr Med J 1996;73:731-733.

15. CSA. The 2006 Population and Housing Census of Ethiopia: Results for the Tigray Region, Central Statistical Authority: Addis Ababa; 2007.

16. Bundy DAP, Hall A, Medley GF, and Savioli L. Evaluating measures to control intestinal parasitic infections. World Health Stat $Q$ 1992;45:168-179.

17. Montresor A, Crompton DWT, Bundy DAP, Hall A, Savioli L. Guidelines for the Evaluation of Soil Transmitted Helminthiasis and Schistosomiasis at the Community Level. Geneva: WHO; 1998:1-49.

18. WHO. Basic Laboratory Methods in Medical Parasitology. Geneva: WHO; 1991.

19. WHO. Prevention and Control of Schistosomiasis and Soil-Transmitted Helminthiasis. WHO Tech Rep Ser. No. 912: 2002; 1 - 57.

20. Barakat R, Farghaly A, El-Masry AG, El-Sayed MK, Hussein MH. The epidemiology of schistosomiasis in Egypt: Patterns of Schistosoma mansoni infection and morbidity in Kafr El-Sheikh. Am J Trop Med Hyg 2000;62:21-27.

21. Palmer DR, and Bundy DA. Epidemiology of human hookworm and Ascaris lumbricoides infestations in rural Gambia. East Afr Med J. 1995;72:527-530.

22. Erko B, and Medhin G. Human helminthiasis in Wondo Genet, southern Ethiopia, with emphasis on geohelminthiasis. Ethiop Med J 2003;41:333-334.

23. Jemaneh L. Intestinal schistosomiasis and geohelminthiasis in school children in the Dembia Plains, Northwest Ethiopia. Ethiop $J$ Health Dev 1998; 12:237-244.

24. Ayele T, and Tesfayohannes T. The epidemiology of Intestinal schistosomiasis around Lake Zway and its island. Results of 1978-1982 survey. In: Proceedings of Symposium on Human Schistosomiasis in Ethiopia, Teklmariam Ayele and Lo. C. T (eds). Addis Ababa University Press, 1982;9-14.

25. Handzel T, Karanja DMS, Addiss DG, Hightower AW, Rosen DH, Colley DG, Andove J, Slutsker L, Secor WE. Geographic distribution of schistosomiasis and soil-transmitted helminths in western Kenya: Implications for anthelminthic mass treatment. Am J Trop Med Hyg 2003;69:318-323. 